\title{
UM CURRÍCULO NO CONTEXTO DO PROGRAMA MAIS MÉDICOS, SUAS DEMANDAS E POSSIVEIS EFEITOS CULTURAIS
}

\author{
Maria Patricia Silva $\left.{ }^{*}\right)$ \\ Marlucy Alves Paraiso ${ }^{(* *)}$
}

A temática problematizada neste trabalho ainda é pouco analisada no campo curricular e pesquisas que tratam do currículo que forma médicos no Brasil. ${ }^{1}$ Consideramos, no entanto, ser este um debate profícuo e relevante. Afinal é necessário usar os estudos curriculares para discutir os currículos que formam médicos. A profissão médica é basilarmente constituída em uma cultura ligada a certo status social. Isso porque a carreira de médico envolve um "estereótipo de profissão com alto grau de autonomia técnica (saber) e econômica (mercado de trabalho)" (MACHADO, 1997, p. 21) e foi constituída desde sua criação para os filhos da elite brasileira (CORADINI, 2005). Trata-se de uma profissão que representa grandes demandas para atender necessidades da população periférica no Brasil. Diante de tal cenário, em 2013, o governo federal criou o "Programa Mais Médicos" (PMM), por meio da Lei 12. 871, sendo parte de seus principais objetivos: o provimento emergencial de médicos, a criação de mais vagas na graduação e residências e novos cursos, baseados nas Diretrizes Curriculares revisadas (BRASIL, 2013).

Ao debruçar sobre o PMM usamos uma perspectiva curricular que nos permite considerar que existe um currículo posto na integração ensino-serviço. A própria formação de médicos e a preocupação com essa integração é uma característica inerente às mudanças recentes do modelo de assistência à saúde no Brasil, a partir da institucionalização do Sistema Único de Saúde (SUS),

\footnotetext{
${ }^{(*)}$ Professora na Universidade do Estado de Minas Gerais (UEMG). Orcid: 〈https://orcid.org/000.0003-4477-2419>. Email: maria.patricia@unimontes.br.

(**) Professora Associada da Faculdade de Educação da Universidade Federal de Minas Gerais, onde atua desde 1995 e do Programa de Pós-graduação em Educação da mesma universidade desde 2003. ORCID: <https://orcid.org/00000002-3542-4650>.E-mail: marlucyparaiso@gmail.com.

${ }^{1}$ No âmbito dos estudos do campo de currículo, especialmente na abordagem pós-crítica, com base em um levantamento realizado no Portal Capes, no período de 2013 até 2018 não foi possível localizar qualquer artigo ou tese que trabalhasse na articulação Currículo e Medicina. Observamos uma ênfase em trabalhos descritivos em relação à grade curricular do curso médico ou a mudanças normativas que alcançam o currículo oficial ministrado nas Escolas Médicas do Brasil - dentre os exemplos citamos: o trabalho de Franco, Cubas e Franco (2014), que analisa as disciplinas do currículo de um curso de Medicina, tendo como referência o perfil do egresso e as competências/habilidades propostas pelas Diretrizes Curriculares Nacionais (DCN) para o curso de Medicina; e o estudo de Pierucci (2011), que foi realizado com objetivo de debater mudanças do currículo de formação médica no Brasil, por meio da problematização das lutas materiais e simbólicas que cercaram a transformação do currículo flexneriano/fragmentado das Escolas de Medicina em currículo de ensino médico adequado ao Sistema Único de Saúde (SUS), com base na medicina comunitária.
} 
reafirmada no PMM. Consideramos em nossa discussão que no PMM há um currículo que educa, estabelece mudanças na prática médica brasileira e explicita conflitos em torno da prática médica existente no Brasil. Afinal o currículo presente no contexto do PMM é um currículo oposto ao que foi tradicionalmente instituído no Brasil, o fundamenta-se em um trabalho especializado, biologicista e voltado para o mercado de trabalho privado.2 Para construir o nosso argumento dividimos o artigo em 04 partes, além da introdução e considerações finais, as quais serão assim apresentadas: uma contextualização sobre a criação do Programa Mais Médicos, seus objetivos para a assistência à saúde da população brasileira, também tratamos da aproximação entre a criação do SUS e dois modelos de assistência à saúde, que afetam o currículo para médicos no Brasil; seguidos dos significados de cultura e currículo; para, apresentar alguns efeitos culturais do Programa Mais Médicos. A relação trabalho e educar inerentes no Programa estariam gestando novas relações, que podem ser identificadas como mudanças na abordagem clínica do PMM, com ações e práticas mais humanísticas e de maneira integral, não fragmentada.

\section{O CAMINHO DA PESQUISA BIBLIOGRÁFICA PARA IDENTIFICAR EFEITOS CULTURAIS DO PMM}

Para localizar os efeitos culturais do Programa foi realizado um levantamento de estudos concernentes à análise sobre o PMM, quando foram consultados trabalhos divulgados na Plataforma de Estudos sobre o Programa Mais Médicos, ${ }^{3}$ tomou como corte o período de janeiro de 2015 até maio de 2018, localizadas 40 pesquisas, ainda em desenvolvimento'. Dessas pesquisas não havia nenhuma que tivesse como objeto principal a relação currículo e PMM.

Em seguida, na mesma Plataforma, realizamos uma consulta entre os artigos publicados, do total de 412 artigos, apenas 15 mencionava o termo "currículo". Mas, por tomarem o significado de “currículo" como o mesmo que "grade curricular", sem menção a práticas médicas e ao currículo conforme desenho aqui proposto, não utilizamos. Assim, uma segunda tentativa foi realizada para localizar relatórios de pesquisa divulgados na Plataforma, nesse caso a busca foi direcionada por dois termos: "educação" e "trabalho médico". No sentido de identificar estudos que conectem

\footnotetext{
${ }^{2}$ Isso é confirmado em diferentes estudos, a existência de uma incompatibilidade no Brasil entre a prática médica e a demanda do SUS, pelo acesso universalizado e equidade, dos quais mencionamos Santos (2015).

${ }^{3}$ Plataforma de Conhecimentos do Programa Mais Médicos - uma iniciativa da Rede de Pesquisa em Atenção Primária à Saúde da Abrasco (Associação Brasileira de Saúde Coletiva) com apoio da OPAS/OMS (Organização Pan-Americana da Saúde/Organização Mundial da Saúde) e do Ministério da Saúde, criada em 2015, para divulgar estudos e trabalhos relacionados ao Programa Mais Médicos.
} 
mudanças sendo postas em prática do trabalho e na prática de educação no contexto do PMM, localizado apenas 01 pesquisa.

Para além da Plataforma Mais Médicos, devido a dificuldade também foi realizado um levantamento entre publicações do campo da saúde coletiva, no período de 2015 a 2018, especialmente nas seguintes revistas: Tempus - Actas de Saúde Coletiva, Saúde e Sociedade e Ciência \& Saúde Coletiva. Foram localizados apenas três artigos que abordavam as temáticas "educação" e "trabalho dos médicos no contexto do PMM".

Em uma terceira tentativa, já no mês de agosto de 2018, foi realizada uma pesquisa em alguns sites de Programas de Pós-Graduação, dos quais citamos a Universidade de São Paulo e o Instituto de Medicina da Universidade do Rio de Janeiro, com o intuito de localizar pesquisas de doutorado ou de mestrado que tivessem como foco a tessitura "Programa Mais Médicos, trabalho, efeitos culturais, currículo e ou educação", foi encontrado um trabalho relacionado na Universidade de São Paulo/Faculdade de Saúde Pública tomamos como recorte temporal o período de 2015 a 2018. Ainda é tomada como parte do estudo uma releitura de entrevistas realizadas pelo autor ${ }^{4}$ (2017) junto aos médicos do Programa Mais Médicos, pesquisa esta realizada em 2017 e intitulada "Programa Mais Médicos: análise do processo de trabalho e da Atenção Primária à Saúde na região metropolitana de Belo Horizonte, Minas Gerais". No que diz respeito aos critérios para a seleção das publicações foram considerados como critérios de inclusão os estudos, artigos e demais publicações que citam o termo "Programa Mais Médicos", "Currículo, "processo de trabalho" e "educação" em seu foco de estudo. ${ }^{5}$

A seguir apresentamos no quadro 01 a relação de artigos e estudos, por autores, a base de pesquisa e, como mencionam algumas das mudanças ocasionadas na relação trabalho e educação no contexto do PMM, o que chamamos nesse artigo de efeitos culturais.

QUADRO 01. Relação de Artigos e estudos por efeitos culturais mencionados

\begin{tabular}{|l|l|l|l|l|}
\hline Tipo de trabalho & Título & Autor & $\begin{array}{l}\text { Efeitos } \\
\text { culturais }\end{array}$ & base de pesquisa \\
\hline Artigo & $\begin{array}{l}\text { Educação em saúde no } \\
\text { Programa Mais Médicos } \\
\text { para o Brasil: O papel do } \\
\text { supervisor no processo } \\
\text { educacional. }\end{array}$ & $\begin{array}{l}\text { RODRIGUES, } \\
\text { QUARESMA E } \\
\text { MONTEIRO, (2015) }\end{array}$ & $\begin{array}{l}\text { Educação } \\
\text { Permanente e } \\
\text { mudança de } \\
\text { práticas }\end{array}$ & $\begin{array}{l}\text { Revista Tempus } \\
\text { Coletiva } \text { Ce Saúde } \\
\text { Brasília }- \text { DF. }\end{array}$ \\
\hline
\end{tabular}

\footnotetext{
4 Para a expressão o "autor 2017", enfatizamos será sempre usada para não mencionar os nomes dos autores com o intuito de garantir o anonimato do presente artigo, devido ao critério de avaliação as cegas solicitado pela Revista.

${ }^{5}$ A escolha das Universidades para pesquisar teses em Programas de Pós-Graduação procedeu de maneira aleatória por conveniência.
} 


\begin{tabular}{|c|c|c|c|c|}
\hline Artigo & $\begin{array}{l}\text { O supervisor e as } \\
\text { estratégias educacionais dos } \\
\text { encontros locorregionais no } \\
\text { Programa Mais Médicos do } \\
\text { Brasil: reflexões acerca de } \\
\text { concepções e práticas. }\end{array}$ & $\begin{array}{l}\text { ENGSTROM et al. } \\
\text { (2016) }\end{array}$ & $\begin{array}{l}\text { Educação } \\
\text { Permanente e } \\
\text { mudança de } \\
\text { práticas }\end{array}$ & $\begin{array}{l}\text { Revista Tempus - } \\
\text { Actas de Saúde } \\
\text { Coletiva, } \\
\text { Brasília-DF. }\end{array}$ \\
\hline Artigo & $\begin{array}{l}\text { Médicos estrangeiros no } \\
\text { Brasil: a arte do saber olhar, } \\
\text { escutar e tocar. }\end{array}$ & SANTOS et al. (2016) & $\begin{array}{l}\text { O encontro } \\
\text { médicos } \\
\text { cubanos e } \\
\text { brasileiros e a } \\
\text { humanização }\end{array}$ & $\begin{array}{l}\text { Revista Saúde e } \\
\text { Sociedade, São } \\
\text { Paulo. }\end{array}$ \\
\hline $\begin{array}{l}\text { Relatório de } \\
\text { Pesquisa }\end{array}$ & $\begin{array}{l}\text { Programa Mais Médicos no } \\
\text { município do Rio de } \\
\text { Janeiro. Mais acesso, } \\
\text { equidade e resolutividade } \\
\text { na APS. }\end{array}$ & $\begin{array}{l}\text { Organização Pan- } \\
\text { Americana de Saúde } \\
(2016)\end{array}$ & $\begin{array}{l}\text { Aprendizado } \\
\text { para médicos } \\
\text { brasileiros }\end{array}$ & $\begin{array}{l}\text { Plataforma } \\
\text { Programa Mais } \\
\text { Médicos }\end{array}$ \\
\hline $\begin{array}{l}\text { Relatório de } \\
\text { Pesquisa }\end{array}$ & $\begin{array}{l}\text { Programa Mais Médicos em } \\
\text { Minas Gerais: uma análise } \\
\text { sobre os principais desafios } \\
\text { e avanços presentes no } \\
\text { processo de trabalho e } \\
\text { assistência na Atenção } \\
\text { Básica em municípios da } \\
\text { Região Metropolitana de } \\
\text { Belo Horizonte/MG. }\end{array}$ & O autor (2017) & $\begin{array}{l}\text { Aprendizagem } \\
\text { na integração } \\
\text { ensino- } \\
\text { serviço, } \\
\text { avanços em } \\
\text { conhecimentos } \\
\text { em relação à } \\
\text { graduação }\end{array}$ & $\begin{array}{l}\text { Relatório de } \\
\text { Pesquisa do } \\
\text { Grupo de } \\
\text { Pesquisa Saúde e } \\
\text { Políticas } \\
\text { Públicas da } \\
\text { Fundação João } \\
\text { Pinheiro, MG. }\end{array}$ \\
\hline $\begin{array}{l}\text { Tese } \\
\text { Doutoramento }\end{array}$ & $\begin{array}{l}\text { Análise do ciclo Político do } \\
\text { Programa Mais Médicos: } \\
\text { cooperação Cuba e Brasil e } \\
\text { seus efeitos no trabalho } \\
\text { médico }\end{array}$ & PAULA (2017) & $\begin{array}{l}\text { Trabalho } \\
\text { médico e } \\
\text { mudança } \\
\text { cultural }\end{array}$ & $\begin{array}{l}\text { Universidade de } \\
\text { São Paulo/ } \\
\text { Faculdade de } \\
\text { Saúde Pública } \\
\text { (on-line) }\end{array}$ \\
\hline
\end{tabular}

Fonte: elaboração própria a partir de pesquisa bibliográfica, 2018.

Os achados apresentados no quadro 01 nos leva a acreditar que, existe ainda um número pequeno de trabalhos que estabeleça a relação entre estudos de currículo - educação para médicos e mudanças nas práticas médicas. Os estudos mencionados não trataram exatamente sobre currículo, mas sobre uma possibilidade de aprendizagem ou educação/formação e consequente mudança na prática médica, no contexto do PMM, por isso foram escolhidas para o estudo.

Ao realizar a leitura dos trabalhos encontramos sinalizações de aberturas, pequenas iniciativas que nos levam a acreditar em mudanças sendo construídas, como por exemplo, a análise realizada por Quaresma, Rodrigues e Monteiro (2015), identificamos uma relação entre os espaços para realizar atividade de educação permanente e mudanças nas práticas médicas. Outro trabalho importante é Tese de Doutoramento, intitulada "Analise do ciclo político do Programa Mais Médicos cooperação Cuba e Brasil e seus efeitos no trabalho médico" Paula (2017), ao mencionar mudanças no trabalho médico no sertão da Paraíba, nos diz também uma mudança cultural e uma nova forma de exercício e acesso aos trabalhos médicos. O que corrobora com nosso entendimento de mudanças como efeitos inerentes ao PMM. 
Para além da busca citada, foram tomados estudos de Girardi, et al. (2016); Giovanella et al. ( 2016); Silva Júnior e Andrade (2016) e de Cyrino et al. (2015), aqui adotados no sentido de complementar o debate, para uma primeira aproximação e contextualização do Programa Mais Médicos. O que compõe matéria fundamental para a compreensão de parte de suas origens e princípios. Dessa maneira, iniciamos nosso debate com parte do contexto e das conexões constituintes do PMM.

\section{O PROGRAMA MAIS MÉDICOS: CONTEXTOS E CONEXÕES}

A criação do Programa Mais Médico, em 2013, reitera os princípios de uma formação integral, inerentes a própria concepção do Sistema Único de Saúde, como parte de um processo complexo e desafiador. Parte dos desafios reside na não aceitação do Programa, por uma parte considerável dos profissionais médicos, tendo em vista que recebeu várias críticas, advindas do meio, bem como de setores da sociedade. ${ }^{6} \mathrm{O}$ PMM somou-se a um conjunto de ações num cenário em que o governo federal assumiu a tarefa de formular políticas públicas para enfrentar problemas que vinham condicionando o desenvolvimento da Atenção Básica à Saúde (ABS) no País (BRASIL, 2015), dentre os quais estava o vazio assistencial ou escassez referente à quantidade de médicos (desigualmente) distribuídos pelo território nacional.

Para a economia, o conceito de escassez mais comum, refere-se aquelas situações nas quais os recursos são insuficientes para atender as demandas. Ao tratar sobre escassez de um bem estamos dizendo que a quantidade existente é insuficiente para satisfazer as necessidades dos indivíduos. Entretanto, a escassez poderá variar em grau (forte/fraca) e sua natureza ser artificial, podendo os governos intervir de maneira tal que o recurso, em questão, atenda a demanda. "No caso da demanda por assistência a saúde, especificamente de médicos, a escassez remete a situações de carência e privação que são incompatíveis com os estados democráticos, uma vez que descrevem

\footnotetext{
${ }^{6}$ As críticas foram veiculadas em diversos jornais escritos e on-line, dos quais cabe mencionar: o Jornal on-line Setor Saúde de São Paulo, em 10 de agosto de 2015, publicava matéria na qual criticava fortemente o PMM e um dos pontos criticados era que o Brasil estaria financiando a, por eles chamada, Ditadura de Cuba; Em 27 de Julho de 2013 o portal intitulado Empresa Brasileira de Comunicação, entre outros fatores tratavam sobre algumas questões, consideradas polêmicas em relação ao programa, principalmente advindas do Conselho Nacional de Medicina (CFM), das quais criticavam o governo que, segundo a instituição, colocava a responsabilidade dos problemas do SUS nos médicos; outro ponto era a não aceitação do CFM da abertura de novas vagas para graduação de novos médicos. Em 2014, o jornal Brasil debate ao analisar o PMM lembrava muitas críticas foram feitas à contratação de médicos cubanos para o programa Mais Médicos, a partir de 2013, especialmente por parte de setores ligados ao PSDB. No entanto, poucos se lembram de que o presidente Fernando Henrique Cardoso já havia contado com o auxílio humanitário de médicos da ilha.
} 
desigualdades no acesso a recursos sociais que podem impactar o curso de vida das pessoas" (GIRARDI, et al. 2016, p.2676).

Ainda, segundo Girardi et al. (2016) o problema da escassez de médicos não acontece apenas no Brasil, agravando em todo o mundo ao longo da primeira década do século XXI. Em relação à população mundial, uma média de 50\% da população vive em áreas remotas e rurais, desse numero menos de $25 \%$ são assistidas pelo trabalho médico. No Brasil, antes da criação do PMM o país tinha cerca de $20 \%$ dos municípios com escassez de médicos, nesse numero estão aqueles de pequeno porte, mais distantes dos grandes centros.

No âmbito da articulação do PMM e o fortalecimento do SUS está uma preocupação em fortalecer a Atenção Básica à Saúde (ou Atenção Primária à Saúde), justamente em áreas de difícil acesso para o provimento de médicos. A ABS ou APS pode ser entendida como o primeiro nível de atenção/atendimento dentro da organização do $\mathrm{SUS}^{7}$ isto é, a porta de entrada no sistema de saúde, que tem entre funções realizar a promoção de saúde e a prevenção de riscos a saúde, em um trabalho integral e que conecte com os outros níveis da atenção à saúde. Espera-se que ação na APS inicie um trabalho na saúde que acolha, escute e ofereça resposta para a maioria dos problemas de saúde da população. E, que possa diminuir danos e responsabilizando-se pela efetividade do cuidado, em conexão com os outros pontos de atenção da rede, garantindo sua integralidade (BRASIL, 2011). Assim, pela premissa da hierarquização dos serviços (BRASIL, 2003) os atendimentos da população antes de chegar no chamado nível de alta complexidade, do atendimento (hospitais), deverá passar pela APS.

A importância da APS para os sistemas de saúde para estruturação da assistência é analisada por Starfield (2001), ao ponderar que nenhuma sociedade dispõe amplamente de recursos econômicos para custear a saúde, em sua concepção mais completa. A atenção superespecializada demanda mais recursos, portanto maiores investimentos financeiros. Dessa maneira, têm menor acesso a ela as pessoas com dificuldade econômica. Nesse ponto, complementamos o fato, reconhecido entre os estudiosos sobre APS, que até $80 \%$ dos problemas de saúde da população são resolvidos na APS (MENDES, 2011). Daí a necessidade de investir em seu fortalecimento. No caso do Brasil, parte estratégica dessa agenda foi a criação do Programa Mais Médicos.

O PMM apresenta entre seus objetivos responder a necessidade de aumentar a oferta de serviços médicos na APS (nas unidades básicas de saúde) o lócus da Estratégia de Saúde da

\footnotetext{
${ }^{7}$ Para maiores detalhes sobre o significado da APS indicamos Starfield (2002), Mendes (2011), Fahel, Silva e Xavier (2018).
} 
Família. ${ }^{8}$ Nesse caso, o programa também prevê como prioritários, para receber os médicos, os municípios das áreas de maior vulnerabilidade social. O PMM direciona suas ações em grandes eixos, dos quais mencionamos: a inserção de novos médicos na Atenção Primária à Saúde, em municípios de menor capacidade de atração; o avanço no número de graduações e residências no País; e uma reconfiguração do processo formativo, estabelecido nas escolas médicas.

$\mathrm{O}$ provimento emergencial aconteceu organizado em ciclos. Na primeira etapa foram recrutados, para atuar em áreas de difícil fixação, médicos de inscrição voluntária com contratos de três anos prorrogáveis por mais três. A seguir, contrataram-se aqueles fornecidos pela cooperação internacional via Organização Pan-Americana de Saúde com Cuba. O registro para atuação desses profissionais é conferido pelo Ministério da Saúde e limitado à prática no âmbito do PMM.

Para o município participar do processo de seleção a prioridade para o provimento de médicos, tomou como regulamentação critérios de enquadramento segundo condições de vulnerabilidade da população. "Em curto prazo, o PMM proporcionou a redução em mais de 50\% dos municípios com escassez de médicos, que passaram de 1.200, no início de 2013, para 558, em setembro de 2014. Na região Norte, 91\% dos municípios com escassez receberam médicos do PMM. Em setembro de 2015 estavam implantados 17.074 médicos do PMM no país" (GIOVANELLA et al., 2016, p. 2700). A medida possibilitou alcançar um incremento de 18.240 médicos em 4.058 municípios brasileiros, o que representa 72,8\% e 34 Distritos Sanitários Especiais Indígenas (DSEI), ação que permitiu a assistência a 63 milhões de pessoas (BRASIL, 2015). O PMM também prevê como estratégia para aumentar o número de médicos formados no Brasil, a criação de novos cursos de Medicina. "Em 2015, o índice de vagas de graduação médica autorizadas por 10 mil habitantes, nas diversas regiões brasileiras foi: Centro-Oeste (1,00 vagas), Nordeste (0,98 vagas), Norte (1,05 vagas), Sudeste (1,20 vagas) e Sul (1,14 vagas), e a média nacional atingiu: 0,81 vagas" (SILVA JUNIOR e ANDRADE, 2016, p. 2670).

O PMM se apresenta, portanto, como uma ação que direcionando para diferentes eixos, se constitui como uma estratégia para atender necessidades de saúde de parte da população brasileira, que sofre com problemas estruturantes que determinam o processo saúde doença, já que são municípios e regiões com considerável grau de vulnerabilidade social e econômica. Nesses lugares

\footnotetext{
${ }^{8}$ Criada em 1994, com o nome Programa de Saúde da Família, hoje a Estratégia de Saúde da Família é fundamental para a organização do Sistema Único de Saúde. "A estratégia de Saúde da Família como forma de territorialização permite a demarcação de um espaço concreto de atuação da equipe de Saúde, tendo o núcleo familiar como base e unidade para o desenvolvimento de sua atuação. Permite, assim, compreender a dinâmica do núcleo familiar, suas relações na sociedade, inclusive o modo social de produção, e avaliar que determinantes sociais contribuem para um melhor ou pior desenvolvimento do processo de saúde nessa comunidade" (BRASIL, 2003, p. 139).
} 
reside, quase sempre, aquela parte da população que, historicamente, teve seu direito à saúde negado. Essa afirmativa fundamenta-se entre outras questões, no fato que o sistema de saúde brasileiro foi construído em uma relação que mistura publico e privado, o qual centralizou o acesso a assistência médica no hospital e como uma medicina privatista (MENICUCCI, 2007).

Nesta linha, outro fenômeno importante é a configuração do modelo de educação médica prioritário no Brasil, ter sido guiado por uma concepção superespecializada (fragmentada) e biomédica, também chamado modelo flexneriano. Na perspectiva flexneriana, um dos pontos fundamentais da educação médica - durante o que é chamado ciclo clínico - deve acontecer no hospital. A doença é considerada apenas em seu caráter biológico e unicausal, como parte de um processo natural. Logo, as dimensões social, psicológica e econômica não contam e não são implicadas no processo saúde-doença. Além da postura positivista, Flexner também via a educação médica como um privilégio apenas para a elite, sem que essa oferecesse espaço para negros ou para mulheres (PAGLIOSA e DA ROS, 2008).

Em oposição a esse modelo, localizamos uma educação para médicos, proposta desde o movimento pela reforma sanitária (AROUCA, 2003), presentes na organização e institucionalização do Sistema Único de Saúde (SUS) e nas Diretrizes Curriculares Nacionais para graduação em Medicina em 2001; reafirmada nas novas Diretrizes Curriculares Nacionais para graduação em Medicina em 2014, que foram renovadas como parte da estruturação do Programa Mais Médicos. Dessa maneira, parte do processo de mudanças e estratégias inerentes ao Programa Mais Médicos está na revisão das Diretrizes Curriculares Nacionais (DCN) para a graduação médica. Conforme observa Cyrino et al. (2015) no escopo, a proposta afirma a centralidade de uma formação em perspectiva que direcione ao trabalho na rede de atenção à saúde no SUS; formação que integre ensino-serviço-comunidade. O que prevalece entre os princípios da APS, uma lógica da educação para médicos em que pese a integralidade e o caráter humanístico, a qual afasta-se da concentração no modelo biomédico, flexneriano.

Assim, fica posta a seguinte reflexão: haverá nas vivencias dos médicos do PMM, um currículo que mobiliza e inicia um desmontar de uma prática profissional flexneriana? Para essas mudanças chamaremos de efeitos culturais. Dizemos que existem no contexto do PMM efeitos culturais, que estão fazendo surgir mutações da prática médica. Para pensar sobre possíveis efeitos culturais, considerando o objetivo desse artigo, articularemos, mesmo que brevemente, uma aproximação com a perspectiva dos Estudos Culturais (EC), sobre significados e imbricações entre currículo e cultura. 


\section{O PROGRAMA MAIS MÉDICOS E POSSÍVEIS APROXIMAÇÕES COM ESTUDOS CULTURAIS}

Os estudos culturais têm origem em 1964, com a criação do Centro de Estudos Culturais Contemporâneos na Universidade de Birmingham (Inglaterra). Desde a criação, este campo de investigação nunca esteve limitado a um campo disciplinar específico - o que representa certa interdisciplinaridade. Os EC ampliam e revigoram conceitos fundamentais, dentre os quais a conexão cultura, identidade e diferença. Nesse campo emerge assim um novo sentido para o currículo: "como um desses espaços em que se dão lutas e conflitos culturais identitários" (PARAÍSO, 2004, p. 54).

Ao tomar a lente dos EC para estudar questões envoltas na configuração de um currículo inerente ao Programa Mais Médicos, merece enfatizar que a contextualização aí assumida penetra uma complexa articulação na qual estarão envolvidos vida cotidianas, agenda política, regimes de verdade, tradição, relações de poder, contextos como sempre plurais. E, portanto suas relações também o são. Nos Estudos Culturais, "as práticas culturais com que operamos, bem como as formas culturais que elegemos considerar, atuam na construção dos contextos e na configuração de formas específicas de organização da vida humana, tendo, portanto, importantes consequências sobre o modo como a realidade se organiza e é vivida" (COSTA; WORTMANN; BONIN, 2016, p.519).

O currículo é aqui compreendido como uma "prática cultural" e como "prática de significação" (SILVA, 2005), que seleciona e divulga sentidos sobre o mundo, sobre as relações sociais, sobre as pessoas (PARAISO, 2005). Tal compreensão traz o conceito de cultura ${ }^{9}$ no entendimento do currículo, já que entende o currículo é "tanto um espaço de divulgação como de produção cultura (PARAISO, 2010, p.35). A cultura é o que dá significado à vida social, "a cultura não é nada mais do que a soma de diferentes sistemas de classificação e diferentes formações discursivas, aos quais a língua recorre a fim de dar significado às coisas” (HALL, 1997, p. 29). Segundo esta ótica, o reconhecimento da prática de significação das formas de vida e da prática social em cada atividade social expressa um significado e confere sentido às ações e relações sociais.

Nesse ponto é possível interpretar a centralidade da cultura a partir de dois aspectos que Hall (1997) chama de "substantivos" e "epistemológicos” pela dimensão substantiva, "o lugar da cultura

\footnotetext{
${ }^{9}$ Ainda que o sentido de cultura entre os antropólogos passe por diferentes conceituações e não esteja limitado a uma única coisa - por exemplo, temos em Geertz (1978) cultura como uma teia de símbolos, tecida pelos homens, onde estão normas, crenças, significados.
} 
na estrutura empírica real e na organização das atividades, instituições, e relações culturais na sociedade, em qualquer momento histórico particular” (HALL, 1997, p. 16) e pela centralidade epistemológica "à posição da cultura em relação às questões de conhecimento e conceitualização, em como a 'cultura' é usada para transformar nossa compreensão, explicação e modelos teóricos do mundo" (HALL, 1997, p. 16), incluindo discussões curriculares e programas sociais.

As culturas podem ser vista como criação e produção; não possuidora de um caráter final. Em face disso, esse autor complementa seu pensamento afirmando que a cultura é possuidora de uma produtividade instável, sempre em movimento e em desconstrução. Além disso, sem limitar-se, se faz como remontagem e construção nas relações de troca e negociações, relações de conflito e relações de poder. Tal como o entendimento de cultura, o "currículo" é uma "prática de significado", de relação social, de relação de poder e como uma prática constitutiva, que produz identidades sociais. "Também o currículo - como a cultura -, como uma trama de significados, pode ser analisado como um discurso e ser visto como uma prática discursiva" (SILVA, 2005, p. 19), que é produtora daquilo que anuncia.

A conexão cultura e currículo nos leva a afirmar que o conhecimento nunca é ensinado de forma estática. Tanto cultura como currículo têm efeitos de criação e produção de sentidos. Assim, entende-se que "as possibilidades" estão postas em um "entre espaço" de criação e no movimento circular da recriação, em todo e qualquer currículo. Dessa maneira, ao pensar no currículo e o PMM como um lugar de encontro entre médicos brasileiros, médicos intercambistas, população assistida (quem nem sempre tiveram acesso ao médico) e isso possibilita conflitos culturais que interferem na (re)significação ou contestação do que é ser médico no Brasil. A (re)significação ou contestação são aqui tomados como efeitos culturais, envoltos no currículo presentes na integração ensinoserviço do PMM. ${ }^{10}$

\section{POSSÍVEIS EFEITOS CULTURAIS DO PROGRAMA MAIS MÉDICOS, LOCALIZANDO INDÍCIOS DE UM CURRÍCULO}

O crescente desenvolvimento tecnológico, as descobertas das ciências naturais, a fragmentação do trabalho e divisão do corpo daí consequente fortaleceram uma concepção instrumental da profissão médica e uma visão unicausal da doença, objetivando os sujeitos ou

\footnotetext{
${ }^{10}$ Um currículo posto no encontro com profissionais de outras nacionalidades, do encontro de médicos com a população que fica a margem, do encontro com o periférico, do encontro com uma prática de serviços de saúde, muitas vezes distantes dos grandes centros e grandes estruturas hospitalares. Na Estratégia de Saúde da Família, nas unidades básicas de saúde que preza por uma organização do trabalho em saúde que seja guiado pela promoção de saúde, integralidade da assistência e uma postura humanística.
} 
transformando-os na doença. As novas diretrizes curriculares, estabelecidas com parte do contexto do PMM, ao incluir como perfil profissional esperado um profissional humanista, reafirmam, portanto, uma preocupação em ultrapassar essa tradição puramente biomédica. Isso em uma perspectiva para uma abordagem clínica dos futuros médicos, em que o processo de formação vivenciado nas escolas médicas possa contribuir com um trabalho de humanizar a atenção à saúde.

Ao pensar nesses processos, conjugados à própria subjetivação de novas dimensões para além da temática instrumental e racional, a qualificação da assistência carece de estratégias que invistam em iniciativas de um "cuidado orientado pelo reconhecimento de pessoa (o sentido de ser membro, de pertencer a um ethos, a uma cultura, a um grupo que define os próprios significados do "eu") e de sujeito (o sentido de uma identidade a partir de uma biografia singular, articulada a uma cultura, capaz de dotar de legitimidade a autonomia de cada um)" (GOULART; CHIARI, 2010, p. 259).

Tarefa desafiadora, complexa, é preciso aqui reconhecer. Entretanto, não impede movimentos contra-hegemônicos, mesmo que o resultado seja micro, mas construído a cada dia na vida do cuidado aos usuários do SUS. Já que as experiências que iniciam ainda convivem com o modelo biomédico/flexneriano, presente nas escolas médicas e nos modelos de assistência. O fato de iniciativas estarem sendo propostas, como as inerentes ao contexto do PMM, exemplifica parte de efeitos culturais, efeitos esses que identificamos, também em meio a conflitos, mas que também estão no aumento do acesso aos serviços médicos por populações carentes. Tais efeitos não são fixos em um espaço/lugar, mas estão em movimento. Nesse contexto, um currículo se faz na vida vivida, diante das necessidades e demandas das comunidades atendidas, o que chamamos de na integração ensino-serviço do Programa Mais Médicos.

Nesse ponto apresentaremos alguns dos efeitos culturais do Programa que articulam aprendizagem, ensino, serviços de saúde que estão em um novo modo de exercer a medicina. Nesse sentido, chamamos atenção para o currículo, portanto para esse processo educação e prática médica, como um artefato cultural, colocando em movimento uma nova forma de ser médico, além daquela cultura profissional que considera a medicina como uma profissão extremamente fragmentada, voltada para a doença e centrada no hospital.

Entre os resultados do trabalho realizado por Rodrigues, Quaresma e Monteiro (2015), ao tratarem sobre a estratégia de educação permanente, ${ }^{11}$ prevista no trabalho de supervisão do PMM,

\footnotetext{
11 A educação permanente em saúde é parte das estratégias e programas do SUS, instituídas desde 2004, por meio de portaria ministério. Desde então sua implantação é um desafio para o sistema de saúde. Dentre outros fatores o esperado
} 
estão as aberturas para um trabalho (co)construtor, atrelado à educação permanente em saúde como um coletivo de conhecimento. No coletivo encontram vivências, o resgate de saberes da comunidade e novas práticas. Assim consideradas, como parte de uma transformação do trabalho médico. Na lógica da educação permanente, os profissionais médicos buscam resolução concreta dos problemas cotidianos, o que também é capaz de mudar a comunidade em que estão inseridos, já que irão debater sobre os problemas de saúde que acometem aquela população. O médico reflete sobre sua prática, sobre os problemas do serviço e constrói uma nova aprendizagem. No processo gestam conhecimentos, em uma dinâmica que pensa o serviço e seus problemas, coloca em prática uma abordagem com esse fim: solução de problemas daquela comunidade.

A Organização Pan Americana de Saúde (OPAS), em um estudo realizado no Rio de Janeiro, aponta que os gestores de saúde reconhecem no PMM um espaço de aprendizagem, educação e troca de saberes. "Desde o começo nós já sabíamos que essa experiência possibilitaria aprendizado de médicos brasileiros, que não possuíam tanto perfil e capacitação para a APS" (Gestor municipal) (OPAS, 2016, p. 48). Outra característica, identificada no mesmo estudo, diz respeito à abordagem médica centrada na pessoa - um dos pilares da medicina de família e de comunidade -, identificada como uma mudança na prática do PMM. Essa abordagem implica o contato entre os médicos e a população de maneira que sejam considerados múltiplos aspectos da vida da pessoa (usuário, paciente), em seu contexto pessoal, familiar e comunitário; o cuidado passa a ser mais humanizado. Logo, os médicos são levados a abandonar aquela perspectiva mais fragmentada e extremamente biomédica.

Para Engstrom et al. (2016), os encontros realizados no PMM provocaram mudanças nas práticas profissionais, pois o Programa constituiu um trabalho preocupado com as necessidades de saúde da população atendida, identificado pelos autores no processo educativo. O processo, acontece na implementação da educação permanente, centrando na problematização e reflexão sobre o que precisa ser aplicado na assistência para atender as próprias demandas do serviço de saúde.

O estudo realizado por Santos et al. (2016) sobre o PMM no Estado do Ceará, confirma mudanças na prática e troca de conhecimento entre médicos brasileiros e estrangeiros, mesmo que

era que iniciativas de Educação Permanente fossem capazes de transformação do trabalho do SUS seguindo três fundamentos centrais: a micropolítica do trabalho, com inspiração marxista e visão ontológica do trabalho, método da roda e problematização/aprendizagem significativa, voltando para questões reais, problemas e necessidades do trabalho em saúde, para localizar também soluções aos problemas identificados pelo grupo. É importante entender que os três elementos estão entrelaçados e em uma lógica que possibilitaria educar um sujeito com compromisso e capacidade de gerar solução de maneira eficaz e eficiente (LEMOS, 2016). 
com pouca intensidade. O ponto principal dessa mudança diz respeito ao atendimento comunicacional e à cultura do cuidado mais humanizado. Assim, confirma uma eficácia inerente ao trabalho no Programa com ações de acolhimento, ${ }^{12}$ por exemplo, que se edifica na própria relação da integração no serviço como aprendizagem de algo novo. Aí localizamos um currículo, um processo de ensino. Logo, efeitos culturais no cuidado e no afeto entre corpos, sendo postos em movimento.

Em pesquisa realizada, em 2017, na região metropolitana de Belo Horizonte, com médicos brasileiros e cubanos, constata-se que houve análise do trabalho no PMM como parte fundamental do processo de aprendizagem e ampliação de conhecimento sobre o funcionamento do SUS e funcionamento da Atenção Primária à Saúde, uma vez que, segundo os entrevistados (no caso dos médicos brasileiros), o currículo formal, pelo qual passaram na graduação, não foi trabalhado profundamente em práticas e desafios da APS. A aprendizagem no currículo, integração ensinoserviço, como artefato, aqui não é tomada como um fim nela mesma, mas um investimento que retoma na qualidade dos serviços prestados à população (o "autor", 2017). O que pode ser identificado na fala a seguir “[...]Eu achei muito interessante. O fazer na Atenção Primária, igual eu te falei, eu acho que isso eu fui percebendo [...]. Hoje tenho um contato maior com a Atenção Primária, e isso daí foi graças ao Programa Mais Médicos (MB04). (O AUTOR, 2017)".

O trabalho em equipe é mencionado por todos os médicos abordados, na mesma pesquisa. Os médicos inseridos no PMM enfatizam a importância do apoio de todos os profissionais da Enfermagem (Enfermeira e Técnico de Enfermagem), o valor do trabalho em conjunto com os Agentes Comunitários de Saúde, como conectores entre a unidade de saúde e as famílias atendidas. O que nos leva a afirmar que há, entre os médicos, valorização e reconhecimento do trabalho em equipe, como parte de um processo de aprendizagem. Nesse caso, os médicos não tratam do trabalho em equipe não em um sentido hierarquizado de poder, mas como um sentido de troca e interdependência no processo de trabalho em saúde. A relação educação, trabalho e saúde ${ }^{13}$ fica evidente como um tripé fundamental para o trabalho na Atenção Primária, como uma forma efetiva

\footnotetext{
${ }^{12} \mathrm{O}$ acolhimento é uma estratégia prevista no Programa Nacional de Humanização, criada pelo Ministério da Saúde, em 2003. A humanização é a valorização dos usuários, trabalhadores e gestores no processo de produção de saúde. Valorizar os sujeitos é oportunizar uma maior autonomia, a ampliação da sua capacidade de transformar a realidade em que vivem, através da responsabilidade compartilhada, da criação de vínculos solidários, da participação coletiva nos processos de gestão e de produção de saúde (BRASIL, 2003, on-line), Disponível em: http://portalms.saude.gov.br/ acoes-e-programas/politica-nacional-de-saude-bucal/legislacao/693-acoes-e-programas/40038-humanizasus>. Acesso em agosto de 2018.

${ }^{13}$ Nas falas dos médicos abordados não identificamos qualquer menção a um trabalho de educação permanente, estabelecido ou ministrado pelos médicos a outros membros da equipe.
} 
de capacitar os profissionais e que contribui com a qualidade dos serviços. Aqui, portanto, está reforçada no discurso dos médicos uma valorização de um dos eixos estruturantes do Programa, que é o investimento na formação de futuros médicos (O AUTOR, 2017).

Na tese de doutoramento de Paula (2017), chama atenção o foco dado aos resultados do Programa que, apesar de todas as críticas recebidas, tornou evidente a beleza de outras lutas cotidianas do serviço nas unidades básicas de saúde do sertão nordestino. Um dos entrevistados fala do "choque" que aconteceu com a chegada do Programa Mais Médicos. O trabalho médico vivido encontra com uma nova cultura, e coloca em "cheque" uma prática médica (tradicional), que era vista como única. É nítida a importância do encontro com essa nova cultura (local), tanto quanto com uma prática de abordagem clínica mais humanizada.

Eles trouxeram pra mim [médicos cubanos] essa questão da humanização, [...] não é humanização utópica, exotérica, bonitinha, não é isso, eu estou falando de política com critérios técnicos, [...] escuta ampliada; preocupação com ambiência, fazer gestão da clínica, coisa que o brasileiro além de não fazer, não faz nem ideia do que é isso (S3) (PAULA, 2017, p. 162).

O PMM trouxe efeitos para uma prática médica que afeta positivamente os profissionais e os usuários dos serviços, a saber, a população mais carente (PAULA, 2017). O Programa atingiu sujeitos que não estavam no fluxo de uma assistência médica, ainda construída como um privilégio no Brasil. Todos os efeitos não estão medidos, mas já é possível perceber resultados da agenda política e social do PMM.

\section{CONSIDERAÇÕES FINAIS}

Os trabalhos aqui estudados possuem uma característica comum, a saber: enfatizam o trabalho dos médicos no PMM com mudanças que preze pela integralidade da assistência. Entre os resultados identificamos que o PMM remontou, colocou em movimento e respondeu a falta. Mas, em sua essência o PMM não limita a responder a essa falta, ou seja, o ponto não é apenas repor uma quantidade de médicos, pois o trabalho médico nessas áreas demanda um cuidado equitativo, uma assistência que se faz mais humanizada e menos fragmentada. Nessa construção podemos dizer que um currículo se abre para "escutar e olhar" o outro, em um trabalho humanizado. O trabalho na APS se estrutura no uso de estratégias que se constroem e se conectam como potencialidade de um cuidado menos tecnicista e menos fragmentado. Portanto, mais integral e humanizado.

Um trabalho que realiza atividades como: visita domiciliar, atividades de educação permanente, acompanhamento longitudinal - o médico acompanha seus pacientes e conhece suas 
histórias e necessidades de saúde, pois o atendimento está ligado a uma área geográfica específica; atividades de promoção de saúde, que muitas vezes acontecem por meio de ações de educação no consultório das unidades básicas de saúde ou em palestras realizadas em parceria com a equipe de saúde. Ao tomar como base estruturante o principio organizativo do SUS da equidade, ao criar o PMM o direciona para atender quem mais necessita e menos têm. O que está produzindo efeitos não apenas para a população assistida, mas também na prática médica, na forma como se exerce a medicina.

Não estamos aqui medindo a intensidade desses efeitos. Mas sim a possibilidade de efeitos inerente ao PMM, localizados e acontecendo em um currículo, presente nas experiências analisadas em cada um desses trabalhos que estudamos para composição desse artigo. O PMM continuará demandando novas pesquisas. Ainda há lacunas, especialmente aquelas que conectem currículo e o trabalho médico a partir do discurso dos próprios médicos. É importante ouvir os médicos que trabalham ou trabalharam no programa, tanto os brasileiros como os estrangeiros. De todo modo é evidente que nos processos de vivência e implementação do Programa está em movimento mudanças e emergem efeitos culturais de grande importância em um pais como o Brasil ainda com tanta carência de atendimento à saúde sobretudo em regiões mais distantes dos grandes centros. 


\section{REFERÊNCIAS}

AROUCA, A.S. O Dilema Preventivista: contribuição para a compreensão e crítica da Medicina Preventiva. São Paulo/Rio de Janeiro: Editora UNESP/FICRUZ, 2003.

BRASIL. Ministério da Educação. Conselho Nacional de Educação. Câmara de Educação Superior. Resolução CNE/CES n. 4, 7 nov. 2001. Institui diretrizes curriculares nacionais do curso de graduação em medicina. Diário Oficial da União. Brasília, 9 nov. 2001; Seção 1, p. 38.

Para entender a gestão do SUS / Conselho Nacional de Secretários de Saúde. Brasília: CONASS, 2003. Disponível em:< http://bvsms.saude.gov.br/bvs/publicacoes/para entender_gestao.pdf $>$. Acesso em: dez. 2016.

Portaria 2.488, de 21 out. 2011. Aprova a Política Nacional de Atenção Básica, estabelecendo a revisão de diretrizes e normas para a organização da Atenção Básica, para a Estratégia Saúde da Família (ESF) e o Programa de Agentes Comunitários de Saúde (PACS). Disponível em:< http://bvsms.saude.gov.br/bvs/saudelegis/gm/2011/prt2488 21 10_2011.html>. Acesso em dezembro de 2016.

. Lei 12.871, de 22 out. 2013. Institui o Programa Mais Médicos, altera a lei 8.745, de 9 de dezembro de 1993, e $\mathrm{n}^{\mathrm{o}}$ 6.932, de 7 de julho de 1981. Diário Oficial da União. Brasília, DF, 2013. Disponível em:< http://www.planalto.gov.br/ccivil_03/_Ato2011-2014/2013/Lei/L12871.htm>. Acesso em dezembro de 2016.

CYRINO E. G. et al. O Programa Mais Médicos e a formação no e para o SUS: por que a mudança? Escola Anna Nery. v.19, n.1, p. 5-10. 2015.

CORADINI, Odaci Luiz. A formação da elite médica, a Academia Nacional de Medicina e a França como centro de importação. Revista Estudos Históricos, Rio de Janeiro, v. 1, n. 35, p. 3-22, jul. 2005. Disponível em:<http:// bibliotecadigital.fgv.br/ojs/index.php/reh/article/view/2232>. Acesso em: maio de 2018.

COSTA, M. V. WORTMANN, M. L. BONIN, I.T. Contribuições dos estudos culturais às pesquisas sobre currículo uma revisão. Currículo sem Fronteiras, v. 16, n. 3, p. 509-541, set./dez. 2016. Disponível em: <http://www. curriculosemfronteiras.org/vol16iss3articles/costa-wortmann-bonin.pdf>. Acesso em maio de 2018.

ENGSTROM et. al. O supervisor e as estratégias educacionais dos encontros locorregionais no Programa Mais Médicos do Brasil: reflexões acerca de concepções e práticas. Tempus, actas de saúde coletiva, Brasília, v. 10, n. 1, 241-252, mar, 2016. Disponível em:< http://www.tempusactas.unb.br/index.php/tempus/article/view/1863/1594 >. Acesso em abril de 2018.

GEERTZ, C. A interpretação das culturas. Rio de Janeiro: Zahar, 1978.

GIRARDI, Sábado Nicolau et al. Impacto do Programa Mais Médicos na redução da escassez de médicos em Atenção Primária à Saúde. Ciência saúde coletiva, Rio de Janeiro , v. 21, n. 9, p. 2675-2684, Sept. 2016 . Disponível em: <http://www.scielo.br/scielo.php?script=sci_arttext\&pid=S1413-81232016000902675\&lng=en\&nrm=iso >. Acesso em setembro de 2017.

GIOVANELlA, Ligia et al. A provisão emergencial de médicos pelo Programa Mais Médicos e a qualidade da estrutura das unidades básicas de saúde. Ciênc. saúde coletiva, Rio de Janeiro , v. 21, n. 9, p. 2697-2708, set. 2016 . Disponível em: $<$ http://www.scielo.br/scielo.php?script=sci_arttext\&pid=S1413-81232016000902697\&lng=en\&nrm= $\underline{\text { iso }}>$. Acesso em setembro de 2017.

GOULART, Bárbara N. Garcia CHIARI, Brasília Maria. Humanização das práticas do profissional de saúde: contribuições para reflexão. Ciência e saúde coletiva, Rio de Janeiro, v. 15, n. 1, p. 255-268, jan. 2010 . Disponível em: $\langle$ http://www.scielo.br/scielo.php?script=sci arttext\&pid=S1413-81232010000100031\&lng=en\&nrm=iso $>$. Acesso em dezembro de 2016.

HALL, Stuart. A centralidade da cultura: notas sobre as revoluções culturais do nosso tempo. Revista Educação \& Realidade, Porto Alegre: UFRGS, vol. 22, p. 15-46, 1997.

Da diáspora - identidades e mediações. Belo Horizonte: Editora UFMG; Representação da UNESCO no Brasil (Humanitas), 2003.

MACHADO, M.H. (Coord.). Os médicos no Brasil: um retrato da realidade. [on-line]. Rio de Janeiro: Editora FIOCRUZ, 1997. 244 p. Disponível em:< http://books.scielo.org/id/bm9qp/pdf/machado-9788575412695-03.pdf $>$. Acesso em dezembro de 2015.

MENDES, E. V. As redes de atenção a saúde. Brasília, DF: OPAS, 2011.

MENICUCCI, T. M. G. Público e privado na política de assistência à saúde no Brasil: atores, processos e trajetória. Rio de Janeiro: Fiocruz, 2007. 
ORGANIZAÇÃo PAN-AMERICANA DA SAÚDE. Programa Mais Médicos no município do Rio de Janeiro. Mais acesso, equidade e resolutividade na APS. Brasília, DF: OPAS, 2016. (Série Estudos de Caso Sobre o Programa Mais Médicos 2). Disponível em:< http://maismedicos.bvsalud.org/programa-mais-medicos-no-municipio-do-rio-dejaneiro/>. Acesso em março de 2018.

PAGLIOSA, F.L.; DA ROS, M.A. O relatório Flexner: para o bem e para o mal. Revista brasileira de educação medica, Rio de Janeiro, v. 32, n. 4, p. $492-499$ dec. 2008. Disponível em: $<$ http://www.scielo.br/scielo.php? script= sci_arttext\&pid=S0100-55022008000400012\&lng=en\&nrm=iso >. Acesso em 2017.

PARAÍSO, Marlucy Alves. Contribuições dos Estudos Culturais para o currículo. Presença Pedagógica, Belo Horizonte, v. 10, n. 55, p. 53-61, jan./fev. 2004.

. O autogerenciamento de docentes em sua formação e em seu trabalho. Educação e Pesquisa, São Paulo, v. 31 , n. 2, p. 173-188, maio/ago. 2005.

. Diferença no currículo. Cadernos de Pesquisa, São Paulo, v. 40, n. 140, p. 587-604, 2010.

PAUlA, J.B. Análise do ciclo Político do Programa Mais Médicos: cooperação Cuba e Brasil e seus efeitos no trabalho médico. 2017. Tese (Doutorado em Saúde Global e Sustentabilidade) - . Faculdade de Saúde Pública, Universidade de São Paulo, 2017. Disponível em :< http://www.teses.usp.br/teses/disponiveis/6/6140/tde-04012018165436/pt-br.php>. Acesso em agosto de 2018.

RODRIGUES, C. P.; QUARESMA, M. S.M.; MONTEIRO, R. C. Educação em saúde no Programa Mais Médicos para o Brasil: O papel do supervisor no processo educacional. Tempus, actas de saúde coletiva, Brasília, v. 9, n. 4, 151158, dez. 2015. Disponível em: < http://www.tempusactas.unb.br/index.php/tempus/article/view/1730/1479\%3 > Acesso em abril de 2018.

SANTOS, João Bosco Feitosa dos et al. Médicos estrangeiros no Brasil: a arte do saber olhar, escutar e tocar. Saúde e Sociedade. São Paulo, v. 25, n. 4, p. 1003-1016, dez. 2016 .Disponível em :<http://www.scielo.br/scielo. php?pid=S0104-12902016000401003\&script=sci_abstract\&tlng=pt>. Acesso em 2017.

SILVA JUNIOR, A.G.; ANDRADE, H.S. Formação médica no Programa Mais Médicos: alguns riscos. Ciência e Saúde Coletiva, Rio de Janeiro, v. 21, n. 9, p. 2670-2671, 2016. Disponível em: <https://www.scielosp.org/article/ ssm/content/raw/?resource_ssm_path=/media/assets/csc/v21n9/1413-8123-csc-21-09-2670.pdf >. Acesso em agosto de 2017.

SILVA, Tomaz Tadeu. Documentos de Identidade: uma introdução às teorias do currículo. Belo Horizonte: Autêntica, 2005 .

. Os Novos Mapas Culturais e o Lugar do Currículo numa Paisagem Pós-Moderna. In: SILVA, Tomaz Tadeu; MOREIRA, Antonio F. (Orgs.). Territórios Contestados: o currículo e os novos mapas políticos e culturais. 6. ed. Petrópolis: Vozes, 1995. p. 184-202.

STARFIELD, B. Atención Primaria: equilibrio entre necesidades de salud, servicios y tecnología. Barcelona: Masson, 2001 . 


\section{RESUMO}

O artigo discute a relação dos currículos e a formação de médicos, temática ainda pouco explorada tanto no campo curricular. Uma pesquisa bibliográfica sobre estudos que analisaram práticas médicas no Programa Mais Médicos (PMM). O objetivo identificar mudanças na formação de médicos, desencadeadas pelas demandas do PMM, tomando como base teórica os estudos culturais. No contexto do Sistema Único de Saúde políticas alcançam o currículo formal - e recentemente - a implementação do PMM, tais ações são identificadas como possibilidades, criadas onde acontecem novas práticas da abordagem médica. Os resultados apontam mudanças na prática do PMM, com efeitos culturais na prática da integração ensinoserviço, por um trabalho humanizado e integral.

Palavras-chave: Currículo. Estudos Culturais. Medicina.

\section{A CURRICULUM IN THE CONTEXT OF THE MORE MEDICAL PROGRAM, ITS REQUESTS AND POSSIBLE CULTURAL EFFECTS}

\section{ABSTRACT}

The article discusses the relationship of curricula and the training of physicians, a subject that is still little explored in the curricular field. A bibliographical research on studies that analyzed medical practices in the More Medical Program (PMM). The objective is to identify changes in the training of physicians, triggered by the demands of the PMM, based on cultural studies. In the context of the Unified Health System policies reach the formal curriculum - and recently - the implementation of the PMM, such actions are identified as possibilities, created where new practices of the medical approach occur. The results point to changes in the PMM practice, with cultural effects in the practice of teaching-service integration, for a humanized and integral work.

Keywords: Curriculum. Cultural Studies. Medicine.

\section{UN CURRÍCULO EN EL CONTEXTO DEL PROGRAMA MÁS MÉDICOS, SUS DEMANDAS Y POSIBLES EFECTOS CULTURALES}

\section{RESUMEN}

El artículo discute la relación de los currículos y la formación de médicos, temática todavía poco explorada tanto en el campo curricular. Una investigación bibliográfica sobre estudios que analizaron prácticas médicas en el Programa Más Médicos (PMM). El objetivo de identificar cambios en la formación de médicos, desencadenadas por las demandas del PMM, tomando como base teórica los estudios culturales. En el contexto del Sistema Único de Salud políticas alcanzan el currículo formal - y recientemente - la implementación del PMM, tales acciones se identifican como posibilidades, creadas donde ocurren nuevas prácticas del abordaje médico. Los resultados apuntan cambios en la práctica del PMM, con efectos culturales en la práctica de la integración enseñanza-servicio, por un trabajo humanizado e integral.

Palabras clave: Currículo. Estudios Culturales. Medicina. 